\title{
Age-associated decrease in ventricular response to haemodynamic stress during beta-adrenergic blockade
}

\author{
FRANK C. P. YIN, GARY S. RAIZES, THOMAS GUARNIERI, \\ HAROLD A. SPURGEON, EDWARD G. LAKATTA, NICHOLAS J. FORTUIN, \\ AND MYRON L. WEISFELDT
}

From the Gerontology Research Center, National Institute on Aging, Baltimore, Maryland 21224;

and the Cardiology Division, Department of Medicine, Fohns Hopkins Medical Institutions,

Baltimore, Maryland 21205, USA

SUMMARY The left ventricular response to haemodynamic stress was compared in 17 normal young (mean 29 years) and 11 normal old (mean 68 years) men. Echocardiographic measurements of left ventricular end-diastolic dimension, left ventricular end-systolic dimension, and velocity of circumferential fibre shortening were made at rest and during $30 \mathrm{mmHg}$ increases in systolic blood pressure induced by handgrip exercise or phenylephrine infusion. At rest there was no age difference in heart rate, left ventricular end-diastolic dimension, left ventricular end-systolic dimension, or circumferential fibre shortening. Both handgrip and phenylephrine induced significant changes in these indices in both age groups but no age difference in the responses could be elicited. In order to eliminate the influence of beta-adrenergic drive, the measurements were repeated during propranolol block. While there was no age difference in ventricular response during beta-blockade at rest, phenylephrine infusion during beta-blockade induced greater increase in left ventricular end-diastolic dimension in the elderly group $(2.3 \pm 0.6 \mathrm{~mm})$ compared with the young group $(0.1 \pm 0.5 \mathrm{~mm}, \mathrm{P}<0.01)$. This increase in the elderly group occurred despite a significantly smaller decrease in heart rate than in the young group. The normal aged human heart performs as well as a young heart at rest and during beta-blockade but has a greater reliance on beta-adrenergic drive during haemodynamic stress.

Previous studies have shown the usefulness of M-mode echocardiography in assessing left ventricular function during handgrip exercise (Stefadouros et al., 1974) and phenylephrine infusion (Redwood et al., 1974; Hirshleifer et al., 1975) in normal and diseased hearts. Earlier studies from this and other laboratories (Sjögren, 1971; Gardin et al., 1977; Gerstenblith et al., 1977) have also shown the feasibility of using this technique to detect age changes in ventricular function and dimensions. Therefore, it appeared that echocardiography could be used as a noninvasive method of determining the effects of aging on the ability of the left ventricle to respond to haemodynamic stress.

Previous studies suggest that the old heart functions as well as the young heart under normal conditions but may have a diminished response

Received for publication 16 January 1978 under some severe stress conditions (Weisfeldt et al., 1971b; Lee et al., 1972; Gerstenblith et al., 1976; Abu-Erreish et al., 1977). Since the ventricular response to stress is mediated in part by betaadrenergic stimulation, age differences in response to a mild stress might be manifested only after betaadrenergic blockade. To test this hypothesis, the left ventricles of a normal population of elderly and adult men were subjected to mild haemodynamic stresses induced by isometric handgrip exercise or phenylephrine infusion both before and during beta-blockade. Left ventricular response was measured by echocardiography.

\section{Methods}

\section{POPULATION}

The study population consisted of 17 young adult (18 to 34 years) and 11 old (60 to 80 years) male 
volunteers from the Baltimore Longitudinal Study on Aging. These volunteers are examined in detail at $1 \frac{1}{2}$ to 2 -year intervals. Criteria for inclusion as part of the study were as follows: no history of cardiopulmonary disease, normal physical examination, normal pulmonary function tests for age, normal resting electrocardiograms, resting blood pressures of less than $150 / 90 \mathrm{mmHg}$, no use of medications known to affect cardiac function, and negative maximal treadmill exercise test. ${ }^{1}$ During the course of the study, among individuals fulfilling these criteria, those with echocardiograms of sufficient quality (see below) constituted the study population. All were physically active but none could be considered to be a well-trained athlete.

\section{PROCEDURE}

After obtaining informed consent a peripheral intravenous line was placed in an antecubital vein. The subjects were studied in the semisupine position in a darkened room. Standard chest monitor electrocardiographic leads were placed, and heart rates were measured from the QRS complex and recorded by a cardiotachometer. Indirect brachial blood pressures were obtained and recorded on the analogue channel of the echocardiogram by means of an ultrasonic probe and a cuff sphygmomanometer connected to a Sanborn P23Db transducer. Echocardiograms were recorded at end-expiration from a SKI Ekoline placed at the third or fourth intercostal space. The output was recorded on a Honeywell 1856 optical oscillograph. The echocardiograms were recorded first by locating the anterior mitral valve leaflet and then directing the transducer inferolaterally until distinct echoes from the endocardial surfaces of both the left ventricular septum and posterior wall were obtained. Left ventricular dimensions were measured in the region where the posterior mitral valve apparatus was observed (Feigenbaum, 1973). Throughout the sequence of studies described below the transducer was held in place on the subject's chest to minimise the chance of measurement error caused by transducer placement.

The subjects were asked to perform a brief maximal voluntary isometric handgrip contraction. A resting echocardiogram was obtained while heart and blood pressure were simultaneously recorded on the analogue channels. The subjects were then asked to perform a sustained isometric handgrip contraction at 30 per cent of maximal handgrip

\footnotetext{
${ }^{1}$ The test was formed at a speed of $3.5 \mathrm{mph}$, treadmill elevation was increased 3 per cent every 2 minutes until the subject asked for the test to be stopped because of extreme fatigue. In most cases the heart rate exceeded 90 per cent of the subject's age-specific predicted maximal heart rate.
}

contraction without performing a Valsalva manoeuvre. Echocardiograms were recorded at endexpiration when systolic blood pressure rose $30 \mathrm{mmHg}$ above the resting value. After a period of recovery, phenylephrine $(2.2 \mathrm{mg} / \mathrm{min})$ was infused and heart rate, blood pressure, and the echocardiogram were recorded when systolic blood pressure again rose $30 \mathrm{mmHg}$ above the resting value.

Later on the same day the studies were performed during beta-adrenergic blockade. To test the level of beta-adrenergic blockade, we determined the rapid intravenous dose of isoprenaline which caused a reproducible increase of $25 \mathrm{bpm}$ in heart rate above baseline. Baseline heart rate was determined by averaging the highest resting sinus rate before drug injection and that during a placebo injection with normal saline given in a double-blind fashion. Betaadrenergic blockade with propranolol $0 \cdot 15 \mathrm{mg} / \mathrm{kg}$ i.v. was produced and the efficacy of the blockade shown in each subject by giving a challenge of isoprenaline at the dosage which previously produced a $25 \mathrm{bpm}$ increment in heart rate. The block was considered adequate if there was no more than a $2 \mathrm{bpm}$ increment in heart rate in response to the challenge dose. In every case this dose of propranolol produced adequate blockade. Once the betablockade was verified, the echocardiograms were repeated at rest and during handgrip and phenylephrine interventions.

\section{DATA REDUCTION}

From the echocardiograms, measurements of left ventricular end-systolic dimension (LVSD), and end-diastolic dimension (LVDD) were made. The ejection phase indices of velocity of circumferential fibre shortening (VCF) and posterior wall velocity (VPW) were calculated (Hirschleifer et al., 1975). The Fig. shows a typical tracing with the measurement points illustrated. Left ventricular end-systolic dimension was measured at the peak excursion of the posterior endocardial wall and was the distance from the endocardium to the most posterior portion of the left interventricular septum. Left ventricular end-diastolic dimension was measured at the $R$ wave of the QRS complex and was the distance between the left septal and posterior endocardial surfaces. Circumferential fibre shortening was calculated as (LVDD-LVSD)/(LVDD $\times$ LVET) where LVET was the left ventricular ejection time measured from the onset to the peak of posterior wall motion as described in our earlier study (Gerstenblith et al., 1977). Posterior wall velocity was calculated as the maximum excursion of the posterior wall divided by left ventricular ejection time. For each intervention the averages of 3 nonconsecutive beats at end-expiration were used for 


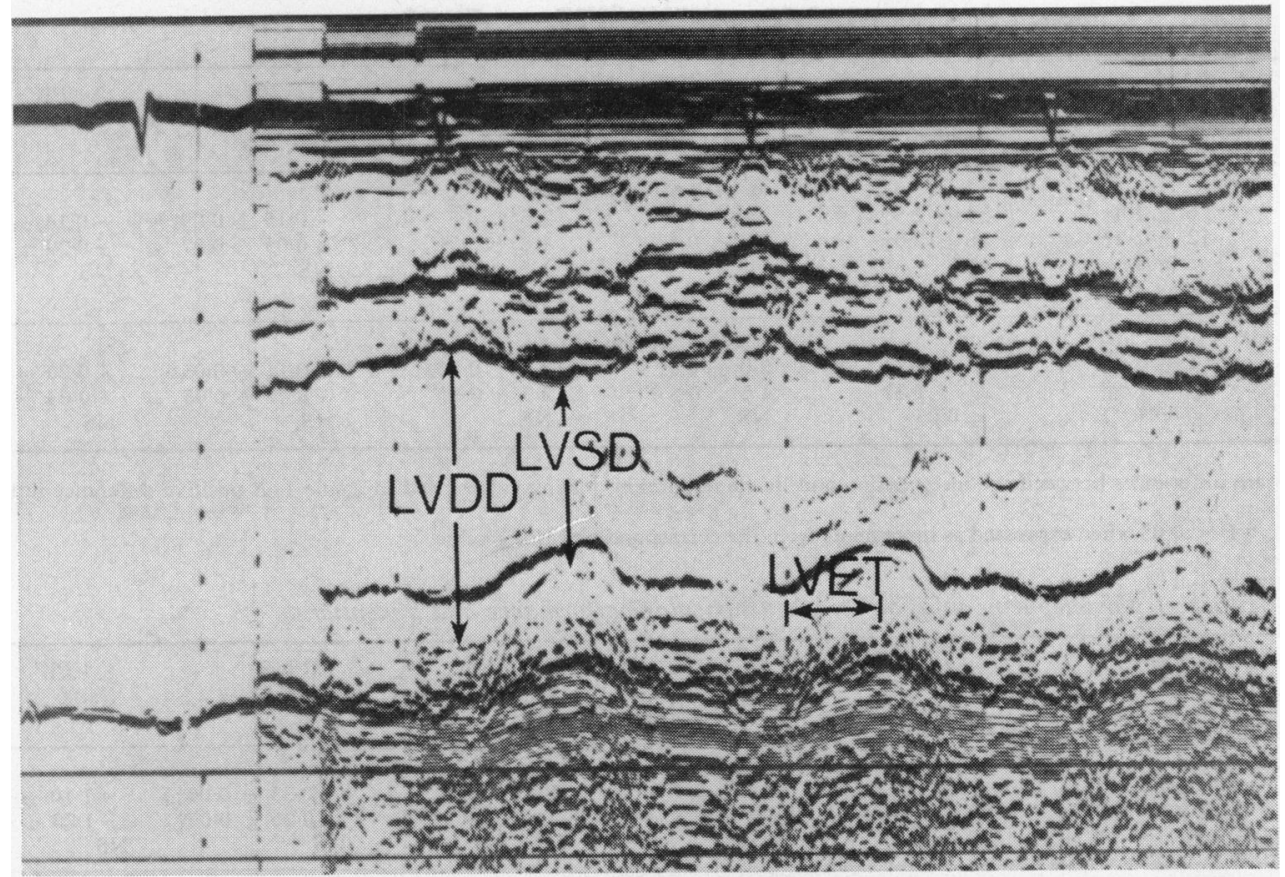

Fig. A typical echocardiogram of the left ventricle. Left ventricular end-diastolic dimension (LVDD), left ventricular end-systolic dimension (LVSD). and ejection time (LVET) were measured as indicated.

analysis since it was shown previously in this laboratory that this number was sufficient for accurate and reproducible results. In a few cases, however, only 2 beats during an intervention were of sufficient quality for analysis. All echocardiograms were measured independently by 2 observers. There was no qualitative difference in the results obtained by either observer so that the results reported herein are those of 1 observer (FY).

The effects of the interventions were assessed by expressing the results as increments from the baseline values. The phenylephrine results are expressed as increments from the respective prehandgrip baseline since preliminary measurements demonstrated that after handgrip the ventricular dimensions rapidly returned to the same baseline values as before handgrip. All results are expressed as mean \pm SEM. Statistical analysis was performed by using paired and unpaired $t$ tests and analysis of variance where appropriate.

\section{Results}

The baseline resting values before and during betablockade for heart rate, systolic blood pressure, left ventricular end-diastolic and end-systolic dimension, circumferential fibre shortening, and posterior wall velocity for the two age groups are listed in Table 1. There was no statistically significant differences between the two age groups in any of

Table 1 Left ventricular performance and dimensions in old and young men at rest

\begin{tabular}{|c|c|c|c|c|c|c|c|c|}
\hline Group & $\begin{array}{l}\text { Age } \\
(y)\end{array}$ & $N$ & $\begin{array}{l}\text { Heart } \\
\text { rate/min }\end{array}$ & $\begin{array}{l}\text { Systolic blood } \\
\text { pressure } \\
(\mathrm{mmHg})\end{array}$ & $\begin{array}{l}\text { LVDD } \\
(\mathrm{mm})\end{array}$ & $\begin{array}{l}L V S D \\
(\mathrm{~mm})\end{array}$ & $\begin{array}{l}V C F \\
(\operatorname{circ} / s)\end{array}$ & $\begin{array}{l}V P W \\
(\mathrm{~cm} / \mathrm{s})\end{array}$ \\
\hline \multicolumn{9}{|c|}{ Before beta-blockade } \\
\hline $\begin{array}{l}\text { Old } \\
\text { Young } \\
\text { P (O vs } Y \text { ) }\end{array}$ & $\begin{array}{l}68.5 \pm 2 \\
29.6 \pm 1 \\
<0.001\end{array}$ & $\begin{array}{l}11 \\
17\end{array}$ & $\begin{array}{l}66 \cdot 0 \pm 2 \cdot 7 \\
69 \cdot 5 \pm 1 \cdot 7 \\
N S\end{array}$ & $\begin{array}{l}129 \pm 1.5 \\
124 \pm 2 \cdot 3 \\
\text { NS }\end{array}$ & $\begin{array}{l}52.0 \pm 1.5 \\
50.4 \pm 0.8 \\
\text { NS }\end{array}$ & $\begin{array}{l}31.5 \pm 1.5 \\
30.5 \pm 0.9 \\
N S\end{array}$ & $\begin{array}{l}1.42 \pm 0.05 \\
1.48 \pm 0.06 \\
\text { NS }\end{array}$ & $\begin{array}{l}4.75 \pm 0.20 \\
5.50 \pm 0.18 \\
\text { NS }\end{array}$ \\
\hline \multicolumn{9}{|c|}{ During beta-blockade } \\
\hline $\begin{array}{l}\text { Old } \\
\text { Young } \\
\mathbf{P}(\mathrm{O} \text { vs } \mathrm{Y})\end{array}$ & $\begin{array}{l}68.5 \pm 2 \\
29.6 \pm 1 \\
<0.001\end{array}$ & $\begin{array}{l}11 \\
17\end{array}$ & $\begin{array}{l}56 \cdot 0 \pm 2 \cdot 5^{\star} \\
61 \cdot 1 \pm 1 \cdot 8^{\star} \\
\text { NS }\end{array}$ & $\begin{array}{l}133 \pm 4 \cdot 7 \\
122 \pm 1 \cdot 5 \\
N S\end{array}$ & $\begin{array}{l}50 \cdot 7 \pm 1.4 \\
50 \cdot 0 \pm 1.0 \\
\text { NS }\end{array}$ & $\begin{array}{l}32.7 \pm 1.5 \dagger \\
33.1 \pm 0.8^{\star} \\
\text { NS }\end{array}$ & $\begin{array}{l}1.15 \pm 0.05^{\star} \\
1.16 \pm 0.04^{\star} \\
\text { NS }\end{array}$ & $\begin{array}{l}3.71 \pm 0.11^{\star} \\
3.81 \pm 0.13^{\star} \\
\text { NS }\end{array}$ \\
\hline
\end{tabular}

$\star P<0.01,+P<0.05$ compared with the value before beta-blockade when expressed as increments from the preblockade value. 
Table 2 Effect of handgrip exercise on left ventricular performance and dimensions

\begin{tabular}{|c|c|c|c|c|c|c|}
\hline Group & $\underset{\text { rate/min }}{\triangle \text { Heart }}$ & $\begin{array}{l}\triangle \text { Systolic blood } \\
\text { pressure } \\
(\mathrm{mmHg})\end{array}$ & $\underset{(m m)}{\triangle L V D D}$ & $\underset{(m m)}{\triangle L V S D}$ & $\begin{array}{l}\triangle V C F \\
(\operatorname{circ} / s)\end{array}$ & $\underset{(\mathrm{cm} / \mathrm{s})}{\triangle V P W}$ \\
\hline $\begin{array}{l}\text { Old } \\
\text { Young } \\
\mathbf{P} \text { (O vs } Y \text { ) }\end{array}$ & $\begin{array}{l}6 \pm 1.4 t \\
12 \pm 2.2 t \\
<0.05\end{array}$ & $\begin{array}{l}30 \pm 2 \cdot 5 t \\
28 \pm 2 \cdot 0 t \\
N S\end{array}$ & $\begin{array}{l}\quad \text { Before } b \\
1.0 \pm 0.8 \\
0.3 \pm 0.4 \\
\text { NS }\end{array}$ & $\begin{array}{l}\text { ade } \\
1.5 \pm 0.8 \\
1.8 \pm 0.5 t \\
\text { NS }\end{array}$ & $\begin{array}{l}-0.15 \pm 0.09 \\
-0.05 \pm 0.07 \\
\text { NS }\end{array}$ & $\begin{array}{l}-0.14 \pm 0.34 \\
-0.29 \pm 0.31 \\
\text { NS }\end{array}$ \\
\hline $\begin{array}{l}\text { Old } \\
\text { Young } \\
\mathbf{P}(\mathrm{O} \text { vs } \mathrm{Y})\end{array}$ & $\begin{array}{l}4 \pm 0.8 t \\
10 \pm 1.5 t \\
<0.01\end{array}$ & $\begin{array}{l}32 \pm 2.7 \dagger \\
27 \pm 1.4 t \\
<0.05\end{array}$ & $\begin{array}{l}\text { During betc } \\
2.0 \pm 0.6 \dagger \\
1.6 \pm 0.8 \\
\text { NS }\end{array}$ & $\begin{array}{l}d e^{\star} \\
3.1 \pm 0.8 t \\
2.3 \pm 0.5 t \\
N S\end{array}$ & $\begin{array}{l}-0.11 \pm 0.05 \ddagger \\
-0.07 \pm 0.05 \\
\text { NS }\end{array}$ & $\begin{array}{l}-0.20 \pm 0.14 \\
-0.03 \pm 0.13 \\
\text { NS }\end{array}$ \\
\hline
\end{tabular}

^Numbers are differences between the intervention and its corresponding resting value listed in Table 1 . A positive difference indicates an increase.

$+\mathrm{P}<0.01, \ddagger \mathbf{P}<0.05$ when expressed as increments from the corresponding resting value.

Table 3 Effect of phenylephrine infusion on left ventricular performance and dimensions

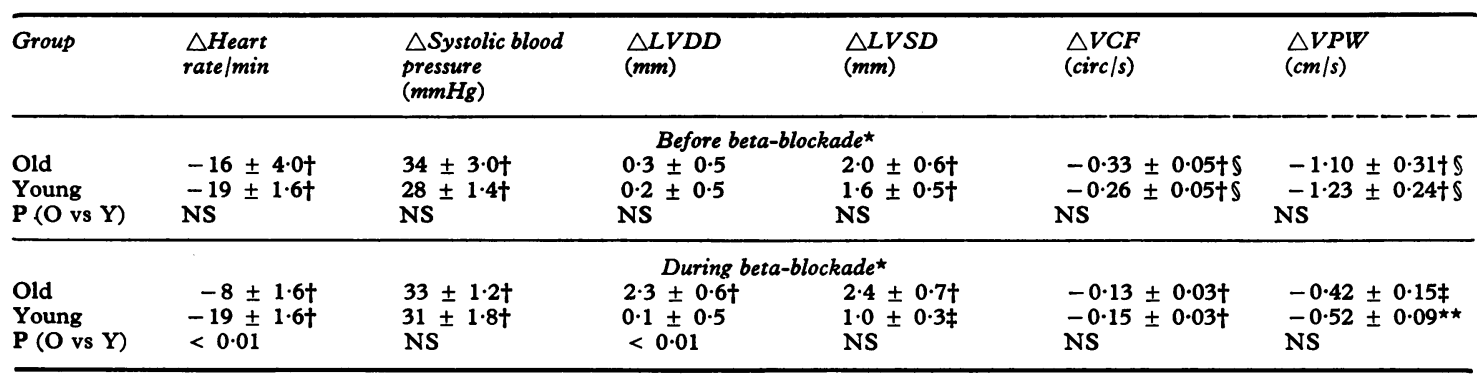

*Numbers are differences between the intervention and its corresponding value listed in Table 1 . A positive difference indicates an increase. $+\mathrm{P}<0.01, \ddagger \mathbf{P}<0.05$ compared with the corresponding resting value.

S P $<0.05, \star \star P<0.01$ compared with the corresponding change during handgrip listed in Table 2.

these variables before beta-blockade. During betablockade the decreases in heart rate, circumferential fibre shortening, and posterior wall velocity and the increase in left ventricular end-systolic dimension in each group were significant $(P<0.01)$ compared with the corresponding preblockade values. Even in the presence of beta-blockade there was no evidence of an age-associated change in left ventricular function in the resting state.

The effects of handgrip exercise before and during beta-blockade are presented in Table 2 . The numbers listed are increments from the respective baseline values with a positive increment representing an increase. This intervention caused an increase in left ventricular end-systolic dimension $(P<0.01)$ before and during beta-blockade but there was no age difference in this response. Handgrip caused heart rate to increase significantly in both age groups with the young group having a greater increase than the old group both before and during beta-blockade. Handgrip induced no other age differences in ventricular response.

The effects of phenylephrine infusion before and during beta-blockade are shown in Table 3. The results are again expressed as increments from the corresponding baseline values. This intervention caused a significant decrease in the ejection indices both before and during beta-blockade. However, there was no age difference in these responses. Accompanying the decrease in ejection indices were increases in left ventricular end-systolic and enddiastolic dimension. The increase in left ventricular end-systolic dimension was not statistically different between the two age groups. During beta-blockade the increase in left ventricular end-diastolic dimension in the old group was significantly greater $(P<0.01)$ than in the young group. It should be noted that the left ventricular end-diastolic dimension increased more in the old than in the young group during beta-blockade despite less slowing of heart rate.

By comparing the corresponding portions of Tables 2 and 3 one can assess the differing effects of the two afterload interventions. Handgrip increased heart rate whereas phenylephrine decreased heart rate both before and during beta-blockade. The old group had less of a heart rate response with handgrip before beta-blockade and with both handgrip and phenylephrine during beta-blockade. The ejection indices were decreased by phenylephrine but not 
by handgrip both before and during beta-blockade. The differences in all the ejection indices between the interventions was significant $(P<0.05)$ before beta-blockade whereas only posterior wall velocity in the young group showed a difference $(P<0.01)$ during beta-blockade. However, for each intervention before and during beta-blockade there was no significant age difference in the ejection indices. The ventricular cavity systolic dimension increased with each intervention but there was no age difference in the change and there was no quantitative difference in the change induced by either intervention before or during beta-blockade.

The ventricular diastolic cavity dimension increased with each intervention only in the old group during beta-blockade but there was no quantitative difference in the change induced by either intervention. The change in left ventricular end-diastolic dimension with phenylephrine resulted in a significantly greater increase in the old compared with the young group. In the old group the beat-to-beat variance in left ventricular end-diastolic dimension was compared with the variance resulting from phenylephrine. The phenylephrine beat-to-beat variance was $21(P<0.001)$ for $1,39 \mathrm{df}$. Thus, the significant change in left ventricular end-diastolic dimension in the old group could not be accounted for by beat-to-beat variation.

\section{Discussion}

M-mode echocardiography has been shown to have significant variations when a subject is studied at different times. Gibson and Brown (1973) and Stefadouros and Canedo (1977) showed that individual variations of up to $11 \mathrm{~mm}$ in left ventricular end-diastolic dimension could be recorded, and ascribed some of this error to slight differences in transducer placement and angulation. In the present study, however, this limitation of the method should not apply since the transducer was not moved from the subject's chest throughout a series of interventions. Moreover, estimates of the beat-to-beat variation in left ventricular end-diastolic dimension were made by Gibson and Brown (1973) who found a root mean square error of $1.6 \mathrm{~mm}$. The previous study from our laboratory (Gerstenblith et al., 1977) using the same techniques as in the present study showed a coefficient of variation in left ventricular end-diastolic dimension of 2 per cent (roughly $1 \mathrm{~mm}$ in this group of subjects). Thus, variation is significantly less on a beat-to-beat basis than in interval studies. Since beat-to-beat variations would be expected to be random, the small $(2.3 \mathrm{~mm})$ but highly significant age difference in left ventricular end-diastolic dimension found in this study is all the more impressive. Comparable magnitudes of changes in left ventricular end-diastolic dimension during phenylephrine were also found by Redwood et al. (1974) and Hirshleifer et al. (1975) $(3.3 \mathrm{~mm}$ and $2.5 \mathrm{~mm}$, respectively).

This study shows that in a group of normal young and normal old men, $30 \mathrm{mmHg}$ haemodynamic stress induced by phenylephrine increased left ventricular diastolic cavity size in the old compared with the young group only during beta-adrenergic blockade. This increase in diastolic dimension in the old occurred despite an equal decrement in the ventricular ejection phase indices in both age groups and despite less of a heart rate decrease in the old group. Before beta-blockade there was no age difference in ventricular response to haemodynamic stress. Both before and during beta-blockade at rest there were no age differences in heart rate, systolic blood pressure, cavity dimensions, or ejection phase indices. This ability of the aged myocardium to maintain normal function except under extreme stress is in agreement with previous results in isolated muscle as well as intact ventricles in both animal models and in man under diverse conditions (Weisfeldt et al., 1971a, b; Lee et al., 1972; Gerstenblith et al., 1976; Abu-Erreish et al., 1977).

Since heart rate was not controlled in this study, the effect of changes in heart rate on changes in dimension and ejection indices could not be directly taken into account. Previous studies have shown that changes in heart rate per se may cause reciprocal changes in the dimensions and parallel changes in ejection phase indices (Smithen et al., 1972; Hirshleifer et al., 1975). In this study the heart rate responses to the two stresses were directionally different, nevertheless there was an increase in dimensions in all cases except one. Therefore, at least a major portion of the change in dimension could be attributed to the stress independent of the changes in heart rate. In addition, since the heart rate in the old group decreased less than the young with phenylephrine during beta-blockade the ageassociated difference in left ventricular end-diastolic dimension response was probably underestimated by not matching heart rates. This diminished baroreceptor response in the old compared with the young group both before and during beta-blockade is in agreement with the previous results of Rothbaum et al. (1974) in rats and Gribbin et al. (1971) in man.

One interpretation of the findings of this study is that the aged heart is more dependent than the young heart on sympathetic nervous system activity to maintain function during stress. When the sympathetic pathway was blocked, another compensatory mechanism, namely use of the FrankStarling mechanism, was used by the old but not the 
young heart to respond to the stress. This diminution of stress response after beta-adrenergic blockade has been previously shown by other methods in normal and diseased hearts (Kahler et al., 1962; Helfant et al., 1971) but has not heretofore been examined in relation to the normal ageing process. Inherent in this interpretation is the assumption that differences in age do not cause the change in the shape of the left ventricle, which occurred in response to these interventions. Assessment of this assumption awaits further investigation. Another assumption that there was no age difference in the disparity between indirect brachial and central aortic pressures is well documented (Kroeker and Wood, 1955; Rowell et al., 1968). There are no data available that show an age difference in this disparity. However, it might be predicted that the disparity would be greater in the old because of age changes in viscoelastic properties (Learoyd and Taylor, 1966) and responses to vasoactive drugs (Fleisch and Hooker, 1976) that would alter the reflection characteristics of the vascular system (Newman and Gosling, 1973). Thus, the same rise in peripheral pressure would represent less afterload in the old than the young and the age difference seen would be an underestimation of the true difference.

The quantitatively different response of the ejection indices to handgrip and phenylephrine suggest that during handgrip there is an increase in sympathetic activity since the differences were minimised after beta-blockade. This is not surprising since studies have shown that handgrip exercise is mediated by both parasympathetic withdrawal and increased sympathetic activity (Martin et al., 1974). In addition, handgrip elicits a greater increase in plasma noradrenaline level in elderly compared with young men (Ziegler et al., 1976). Since propranolol is a competitive beta-blocking agent, the increased catecholamine level during handgrip exercise during propranolol blockade may have partially reduced the level of blockade achieved. This would help to explain why phenylephrine but not handgrip caused an age-associated increase in ventricular cavity dimensions during beta-blockade.

In conclusion, this study demonstrates that there is no age difference in performance of the normal heart (1) at rest, (2) at rest during beta-adrenergic blockade, or (3) during a haemodynamic stress of $30 \mathrm{mmHg}$ rise in peripheral systolic blood pressure. Only when haemodynamic stress is imposed during beta-blockade does the old heart rely more on its volume reserves than the young heart. Thus, we postulate that the old heart is more dependent than the young heart on sympathetic nervous system control during stress.

\section{References}

Abu-Erreish, G. M., Neely, J. R., Whitmer, J. T., and Sanadi, D. R. (1977). Fatty acid oxidation by isolated perfused working hearts of aged rats. American fournal of Physiology, 232 (3), E258-E262.

Feigenbaum, H. (1973). Echocardiography. Lea and Febiger, Philadelphia.

Fleisch, J. H., and Hooker, C. S. (1976). The relationship between age and relaxation of vascular smooth muscle in the rabbit and rat. Circulation Research, 38, 243-249.

Gardin, J. M., Henry, W. L., Savage, D. D., and Epstein, S. E. (1977). Echocardiographic evaluation of an older population without clinically apparent heart disease (abstract). American fournal of Cardiology, 39, 277.

Gerstenblith, G., Frederiksen, J., Yin, F. C. P., Fortuin, N. J., Lakatta, E. G., and Weisfeldt, M. L. (1977). Echocardiographic assessment of a normal aging population. Circulation, 56, 273-278.

Gerstenblith, G., Lakatta, E. G., and Weisfeldt, M. L. (1976). Age changes in myocardial function and exercise response. Progress in Cardiovascular Diseases, 19, 1-21.

Gibson, D. G., and Brown, D. (1973). Measurement of instantaneous left ventricular dimension and filling rate in man, using echocardiography. British Heart fournal, 35, 1141-1149.

Gribbin, B., Pickering, T. G., Sleight, P., and Peto, R. (1971). Effect of age and high blood pressure on baroreflex sensitivity in man. Circulation Research, 29, 424-431.

Helfant, R. H., DeVilla, M. A., and Meister, S. G. (1971). Effect of sustained isometric handgrip exercise on left ventricular performance. Circulation, 44, 982-993.

Hirshleifer, J., Crawford, M., O'Rourke, R. A., and Karliner, J. S. (1975). Influence of acute alterations in heart rate and systemic arterial pressure on echocardiographic measures of left ventricular performance in normal human subjects. Circulation, 52, 835-841.

Kahler, R. L., Gaffney, T. E., and Braunwald, E. (1962). The effects of autonomic nervous system inhibition on the circulatory response to muscular exercise. Fournal of Clinical Investigation, 41, 1981-1987.

Kroeker, E. J., and Wood, E. H. (1955). Comparison of simultaneously recorded central and peripheral arterial pressure pulses during rest, exercise, and tilted position in man. Circulation Research, 3, 623-632.

Learoyd, B. M., and Taylor, M. G. (1966). Alterations with age in the viscoelastic properties of human arterial walls. Circulation Research, 43, 278-292.

Lee, J. C., Karpeles, M. L., and Downing, S. E. (1972). Agerelated changes of cardiac performance in male rats. American fournal of Physiology, 222, 432-438.

Martin, C. E., Shaver, J. A., Leon, D. F., Thompson, M. E., Reddy, P. S., and Leonard, J. J. (1974). Autonomic mechanisms in hemodynamic responses to isometric exercise. Fournal of Clinical Investigation, 54, 104-115.

Newman, D. L., and Gosling, R. G. (1973). Influence of peripheral vascular state on pressure pulse changes due to total occlusion of the aorta. Fournal of Applied Physiology, 35, 786-789.

Redwood, D. R., Henry, W. L., and Epstein, S. E. (1974). Evaluation of the ability of echocardiography to measure acute alterations in left ventricular volume. Circulation, 50, 901-904.

Rothbaum, D. A., Shaw, D. J., Angell, C. S., and Shock, N. W. (1974). Age differences in the baroreceptor response of rats. Fournal of Gerontology, 29, 488-492.

Rowell, L. B., Brengelmann, G. L., Blackmon, J. R., Bruce, R. A., and Murray, J. A. (1968). Disparities between aortic and peripheral pulse pressures induced by upright exercise and vasomotor changes in man. Circulation, 37, 954-964. 
Sjögren, A.-L. (1971). Left ventricular wall thickness determined by ultrasound in 100 subjects without heart disease. Chest, 60, 341-346.

Smithen, C. S., Warton, C. F., and Sowton, E. (1972). Independent effects of heart rate and exercise on left ventricular wall movement measured by reflected ultrasound. American fournal of Cardiology, 30, 43-47.

Stefadouros, M. A., and Canedo, M. I. (1977). Reproducibility of echocardiographic estimates of left ventricular dimensions. British Heart fournal, 39, 390-398.

Stefadouros, M. A., Gorssman, W., Shahawy, M. E., and Witham, A. C. (1974). The effect of isometric exercise on the left ventricular volume in normal man. Circulation, 49, 1185-1189.

Weisfeldt, M. L., Loeven, W. A., and Shock, N. W. (1971a).
Resting and active mechanical properties of trabeculae carneae from aged male rats. American fournal of Physiology, 220, 1921-1927.

Weisfeldt, M. L., Wright, J. R., Shreiner, D. P., Lakatta, E., and Shock, N. W. (1971b). Coronary flow and oxygen extraction in the perfused hearts of senescent male rats. Fournal of Applied Physiology, 30, 44-49.

Ziegler, M. G., Lake, C. R., and Kopin, I. J. (1976). Plasma noradrenaline increases with age. Nature, 261, 333-335.

Requests for reprints to Dr Edward G Lakatta, Cardiovascular Section, Gerontology Research Center, National Institute on Aging, Baltimore City Hospitals, Baltimore, Maryland 21224, USA. 